\title{
Myomectomy for uterine preservation and fertility
}

\author{
Yelamanchi Savitha Devi*, Yendru Katyayani Swapna, T. Kamalakar Naidu, \\ Ganga Bhavani Vaddiraju
}

Department of Obstetrics and Gynecology, Swapna Health Care, Hyderabad, Telangana, India

Received: 12 April 2019

Revised: 12 May 2019

Accepted: 05 June 2019

\section{*Correspondence:}

Dr. Yelamanchi Savitha Devi,

E-mail: drsavithay@gmail.com

Copyright: () the author(s), publisher and licensee Medip Academy. This is an open-access article distributed under the terms of the Creative Commons Attribution Non-Commercial License, which permits unrestricted non-commercial use, distribution, and reproduction in any medium, provided the original work is properly cited.

\begin{abstract}
Background: Leiomyomas are benign monoclonal smooth muscle tumors that are characterized by cellular mutations, growth factor dysfunction, and abnormalities in the extracellular matrix. The objective of this study was to analyse the patient selection, feasibility, complications and the outcomes of myomectomies done for uterine preservation and fertility.

Methods: Out of 606 myomectomies performed over 23 years at a tertiary care endoscopy centre, retrospective analysis of 358 cases of laparoscopic myomectomy (LM) and 96 cases of abdominal myomectomy (AM) was done.

Results: Myomectomies were done for symptomatic women who wanted to preserve their uterus either to improve fertility or pregnancy outcome. Sizes of myomas tackled by myomectomy ranged from $1 \mathrm{~cm}$ to $20 \mathrm{cms}$. The largest number removed by laparoscopy was 19.9 out of 358 cases scheduled for LM were converted to AM. 6 patients had repeat myomectomy of myomas. About $0.44 \%$ had STUMP and $0.44 \%$ had leiomyosarcoma on HPE. Only 10/199 or $5 \%$ of patients who wanted to preserve their uterus had subsequent hysterectomies. $95 \%$ were satisfied with good symptom relief. $40.1 \%$ in LM and $37 \%$ in AM group conceived.

Conclusions: Majority of the cases were successfully done by laparoscopy. With increasing experience more cases with bigger and multiple myomas could be tackled by laparoscopy. $10.3 \%$ in LM and $45.9 \%$ in AM were $10 \mathrm{cms}-20$ $\mathrm{cms}$. The main method of retrieval was morcellation. There were no major complications. Both the methods were found to be safe, feasible and provided good result. With increasing experience bigger and multiple myomas could be tacked by LM, which has several advantages over AM.
\end{abstract}

Keywords: Abnormal uterine bleeding, Infertility, Leiomyoma, Morcellation, Myomectomy, Parasitic leiomyoma, Uterine preservation

\section{INTRODUCTION}

Leiomyomas are benign monoclonal smooth muscle tumors that are characterized by cellular mutations, growth factor dysfunction, and abnormalities in the extracellular matrix. Both estrogen and progesterone play a key role in the pathogenesis. ${ }^{1}$

Approximately $25 \%$ of women with myomas develop symptoms (depending on the number, location, size and behaviour) like heavy menstrual bleeding (HMB), pressure symptoms (pelvic pressure, urinary urgency and frequency, urinary retention, hydronephrosis, or bowel dysfunction), sub fertility and/or recurrent miscarriage. ${ }^{2}$

They pose a major women's health care problem and interfere not only with her quality of life, but also with her reproductive performance, and constitute one of the commonest indications for hysterectomy.

Most of the women like to preserve their uterus for future child bearing, and sometimes, even when they don't 
desire future child bearing. Hence, there has been a great emphasis on expectant management, medical management and conservative surgical management of uterine myomas.

Women should be made aware of all options of treatments available for myoma management. Medical (GnRha, selective progesterone receptor modulators), non-surgical (uterine artery embolization (UAE)), magnetic resonance guided focused ultrasound surgery (MRgFUS)) and surgical (myomectomy, cryomyolysis, thermocoagulation and hysterectomy) options should be discussed in detail.

The main conservative surgical option is myomectomy by different techniques, laparoscopic, abdominal, vaginal, hysteroscopic and during caesarean section.

\section{METHODS}

A total of 606 cases of myomectomies were performed over a period of 23 years at a tertiary care endoscopy centre, specialized in operative hysteroscopy and operative laparoscopy. Even though the abdominal myomectomies were done from the year 1983, medical records were not available up to 1994 , hence analysis was done only from 1994 (October 1994 to December 2017).

The myomectomies were divided into the following groups:

- $\quad$ Laparoscopic myomectomy (LM) - 347

- Abdominal myomectomy (AM) - 96

- Laparoscopic Assisted Minilap myomectomy (LAM) $-11$

- Submucous fibroid resection (SMFR) by hysteroscopy - 125

- Myomectomy done during caesarean section - 24 .

- Vaginal myomectomy - 3 .

This study comprises of retrospective analysis of 358 cases of LM (including 11 LAM) and 96 cases of AM done during this period, as these constituted the majority. Myomectomies done by hysteroscopy, by vaginal route and during caesarean section were excluded from this study.

The aim of the study was to analyse the patient selection, feasibility, complications and the outcomes of myomectomies done by laparoscopy and abdominal route. The main indication was uterine preservation needed either to improve fertility or for symptomatic relief.

Cases were identified from clinical notes, hospital operating theatre records, consultant diaries and histopathology database. Data were collected on patient demographics (age, parity and menopausal status), presenting symptoms, (abnormal uterine bleeding, pain, pressure symptoms, infertility or recurrent pregnancy loss), pre-operative imaging findings (number, size, location and vascularity of myomas), operative details (number, size of myomas removed, complications, intraoperative blood loss, if breach of the endometrial cavity occurred method of retrieval), post-operative outcomes (duration of inpatient stay, incidence and nature of complications) and histological diagnosis.

Pre-operative evaluation included a detailed history and clinical examination. The presence of scars over the abdomen, the size, shape and the mobility of the uterus, the size of the myomas relative to the size of the pelvis, and impaction of the mass in the pelvis were noted as they help to select the appropriate type of surgery. Transvaginal ultrasonography (TVUS) and myoma mapping were done for every case and MRI was done for specific indications in a few cases.

Procedure to be done was selected depending upon her presenting symptoms, age, desire to preserve fertility or uterus, characteristics of myoma (size, number, location, vascularity, etc.) and her medical and surgical history. Counseling was done in detail regarding the options available and the risks, benefits and complications of each. Informed consent was taken including all these issues, need to use morcellator and the rare chances of Parasitic myomas and spreading of sarcoma if present. No pre-operative medical management was used in Swapna Health Care, Hyderabad, Telangana, India to reduce the size of myoma.

All procedures were done under general anaesthesia, choice being controlled hypotensive anaesthesia. Hysteroscopy was done as a rule for both categories to rule out submucous myomas, endometrial hyperplasias, polyps, septum, synechiae etc.

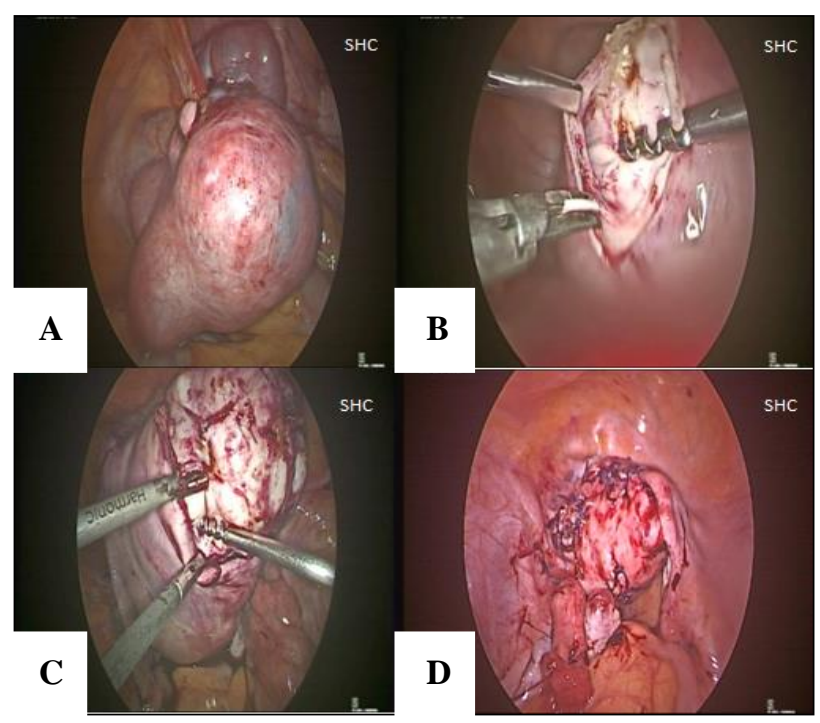

Figure 1: A) Multiple myomas. B) Traction with myoma screw. C) Use of harmonic scalpel. D) After suturing. 
For LM diluted vasopressin was injected to reduce blood loss, site of incision was selected according to the location of myoma over the most prominent part of tumour (Figure 1). Author used monopolar needle in the earlier cases of the series and harmonic scalpel in the later cases to make incision. Plane of cleavage was identified and myomas were enucleated by using traction with myoma screw and counter traction. Minimum possible bipolar energy was used for haemostasis. Suturing was done in 1-3 layers depending on thickness of capsule. Retrieval was done, mostly through electronic morcellator and in a few by posterior colpotomy.


Figure 2: Abdominal myomectomy. A) Large fundal myoma. B) Tunneling. C) Anterior incision and preparation of hood. D) Anterior suture line.

In AM, a tourniquet was applied around lower uterine segment with a soft catheter before making incision and released periodically and finally at the end of surgery (Figure 2). A small abdominal incision to facilitate initial partial myomectomy by morcellation, then mobilization and delivery of the uterus through the incision to complete myomectomy and suturing was the preferred method. To remove large fundal myomas, Bonney's hood operation was done by giving incision anteriorly and by folding the posterior flap of myometrium to get suture line on anterior surface.

For very big myomas LAM was done with an extra 3$4 \mathrm{cms}$ pfannensteil incision, used for enucleation and retrieval of myoma and also for suturing.

\section{RESULTS}

During the study period from 1994-2017 a total of 454 myomectomies were done, 358 by laparoscopy and 96 by abdominal route. A comparative analysis was done between LM and AM as these constituted the majority of surgical procedures. 11 cases of LAM myomectomies were included in LM group.
Respective ranges of ages were 14-48 years in LM group and 18-50 years in AM group. Median age of women who underwent LM was 31 years and AM were 30 years. Maximum numbers were in the age group 26-35 years in the groups, $72.6 \%$ in LM and $60.4 \%$ in AM.
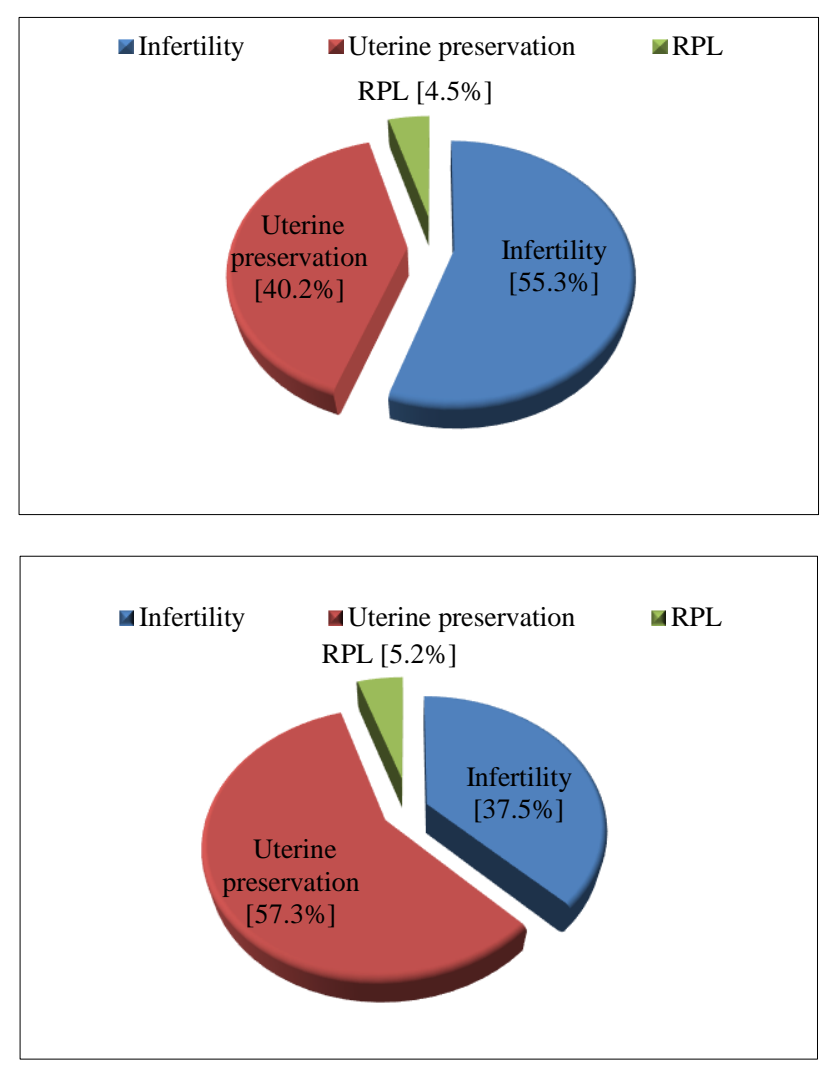

Figure 3: Indications for LM and AM. A) Indications of Laparoscopic myomectomy. B) Indications of Abdominal myomectomy.

The indications were mainly classified into three groups:

- Uterine preservation where the woman wanted symptomatic relief from menorrhagia, dysmenorrhea, pain abdomen, pelvic pain or pressure, but wanted to preserve her uterus

- To improve fertility (primary or secondary)

- For better outcomes in RPL, where no other cause was found (Figure 3).

Sizes of myomas tackled by myomectomy ranged from 1 $\mathrm{cm}$ to $20 \mathrm{cms}$. As the size of the myoma increased the preferred route was more AM than LM (Including LAM). When the myoma was $15-20 \mathrm{cms}$, only $18.8 \%$ were done by LM and $81.82 \%$ were done by AM (Table 1). $41.7 \%$ of AM group had multiple myomas compared to $35.7 \%$ in the LM group. $64.3 \%$ of LM (230) and $58.3 \%$ of AM (56) were done for single myoma and $35.7 \%$ (128) of LM and $41.7 \%$ (40) of AM were done for multiple myomas.

The largest number of myomas removed by LM were 9, AM were 19. 
Table 1: Sizes of myomas and selection of route.

\begin{tabular}{|llllll|}
\hline Sizes & Laparoscopy including (LAM) & $\%$ & Abdominal & $\%$ & Total \\
\hline $1-4.9 \mathrm{cms}$ & $126 / 134$ & 94.03 & $8 / 134$ & 5.97 & 134 \\
\hline $5 \mathrm{cms}-6.9 \mathrm{cms}$ & $112 / 123$ & 91.05 & $11 / 123$ & 8.95 & 123 \\
\hline $7 \mathrm{cms}-9.9 \mathrm{cms}$ & $83 / 116$ & 71.55 & $33 / 116$ & 28.45 & 116 \\
\hline $10 \mathrm{cms}-15 \mathrm{cms}$ & $33 / 59$ & 55.93 & $26 / 59$ & 44.07 & 59 \\
\hline $15 \mathrm{cms}-20 \mathrm{cms}$ & $4 / 22$ & 18.18 & $18 / 22$ & 81.82 & 22 \\
\hline Total & 358 & & 96 & & 454 \\
\hline
\end{tabular}

Table 2: Comparative analysis between LM and AM.

\begin{tabular}{|c|c|c|c|c|c|c|c|c|c|c|c|c|c|c|c|c|}
\hline $\begin{array}{l}\text { Type of } \\
\text { myomec- } \\
\text { tomy }\end{array}$ & $\begin{array}{l}\text { No. } \\
\text { of } \\
\text { cases }\end{array}$ & $\begin{array}{l}\text { Med- } \\
\text { ian } \\
\text { age } \\
\text { (yrs) }\end{array}$ & $\begin{array}{l}\text { Duration } \\
\text { of sur- } \\
\text { gery }\end{array}$ & $\begin{array}{l}\text { Size } \\
>10 \\
\mathrm{cms} \\
(\%)\end{array}$ & $\begin{array}{l}\text { Multi- } \\
\text { ple } \\
\text { myomas } \\
(\%)\end{array}$ & $\begin{array}{l}\text { Largest } \\
\text { num-ber } \\
\text { removed } \\
\text { (n) }\end{array}$ & $\begin{array}{l}\text { Pre- } \\
\text { op } \\
\text { blood } \\
\text { trans- } \\
\text { fusion } \\
(\%)\end{array}$ & $\begin{array}{l}\text { Intra \& } \\
\text { post-op } \\
\text { blood } \\
\text { trans- } \\
\text { fusion } \\
(\%)\end{array}$ & $\begin{array}{l}\text { Repeat } \\
\text { myo- } \\
\text { mectomy } \\
\text { (n) }\end{array}$ & $\begin{array}{l}\text { Sym- } \\
\text { ptom } \\
\text { relief } \\
(\%)\end{array}$ & $\begin{array}{l}\text { Hysterect- } \\
\text { omy (\%) }\end{array}$ & $\begin{array}{l}\text { Con- } \\
\text { ceptions } \\
\text { in In- } \\
\text { fertility } \\
(\%)\end{array}$ & $\begin{array}{l}\text { Con- } \\
\text { ceptions } \\
\text { in RPL } \\
(\%)\end{array}$ & $\begin{array}{l}\text { Para- } \\
\text { sitic } \\
\text { myoma } \\
\text { (n) }\end{array}$ & $\begin{array}{l}\text { Leiom- } \\
\text { yo sar- } \\
\text { coma } \\
\text { (n) }\end{array}$ & STUMF \\
\hline \multirow{2}{*}{ LM } & \multirow{2}{*}{358} & \multirow{2}{*}{31} & \multirow{2}{*}{$\begin{array}{l}2 \mathrm{hrs} \\
15 \mathrm{~min}\end{array}$} & 10.3 & 35.7 & \multirow{2}{*}{9} & \multirow{2}{*}{2.24} & \multirow{2}{*}{2.8} & \multirow{2}{*}{6} & \multirow{2}{*}{98.6} & \multirow{2}{*}{1.39} & \multirow{2}{*}{40.1} & \multirow{2}{*}{37.5} & \multirow{2}{*}{2} & \multirow{2}{*}{2} & \multirow{2}{*}{2} \\
\hline & & & & $37 / 358$ & $128 / 358$ & & & & & & & & & & & \\
\hline \multirow{2}{*}{$\mathrm{AM}$} & \multirow{2}{*}{96} & \multirow{2}{*}{30} & $2 \mathrm{hrs}$ & 45.9 & 41.7 & \multirow{2}{*}{19} & \multirow{2}{*}{17.7} & \multirow{2}{*}{7.3} & \multirow{2}{*}{-} & \multirow{2}{*}{94.8} & \multirow{2}{*}{5.2} & \multirow{2}{*}{37} & \multirow{2}{*}{60} & \multirow{2}{*}{-} & \multirow[b]{2}{*}{-} & \multirow{2}{*}{-} \\
\hline & & & $20 \mathrm{~min}$ & $44 / 96$ & $40 / 96$ & & & & & & & & & & & \\
\hline
\end{tabular}

Mean duration of surgery was 2 hours 50 min for LM, 2 hours $20 \mathrm{~min}$ for AM. Average hospital stay for LM was 24 hours-48 hours, AM was 72 hours. 9 out of 358 (2.5\%) cases scheduled for LM were converted to AM. 25 patients had pre-operative blood transfusions to improve anaemia and 17 patients had intra-operative and post-operative transfusions when blood loss was more than $1000 \mathrm{ml} .6$ patients had repeat myomectomy, gap between original and repeat myomectomies was 1 to 14 years with mean gap of 7 years.

About 5 out of $358(1.39 \%)$ patients in LM and 5 out of $96(5.2 \%)$ patients in AM underwent hysterectomy at a later date. Out of 199 patients in both groups who wanted to preserve their uterus, only $10(5 \%)$ had subsequent hysterectomies. $95 \%$ of patients could avoid hysterectomy, as they had total relief from their symptoms.

Infertility was the indication in $198(55.3 \%)$ of LM and $36(37.5 \%)$ in AM. Out of these 50 (41 in LM and 9 in AM) were lost for follow-up or referred back to the respective doctors or ART centers who referred them to us for myomectomy.

Out of remaining 157 in LM, 63 conceived (40.1\%) and out of 27 in AM, 10 conceived (37\%). About 21 patients presented with RPL (16 from LM and 5 from AM), and myomectomy was done to improve pregnancy outcome as myoma was found to be the main reason.

Out of 21 cases, 9 (42.85\%) conceived. Two patients in our series of LM had parasitic myomas. Out of 454 cases of myomectomies, histopathological examination confirmed benign leiomyoma in 450 (99.1\%). 2/454 $(0.44 \%)$ had smooth muscle tumor of uncertain malignant potential (STUMP) and $2(0.44 \%)$ had leiomyosarcoma. Finally, the results of comparative analysis between LM and AM presented in Table 2.

\section{DISCUSSION}

Majority of the cases were successfully done by laparoscopy. The success of laparoscopic myomectomy is defined as a procedure carried out by minimally invasive approach, without need for conversion to open surgery, which results in a complete removal of myomas selected for surgical excision, without any major complications.

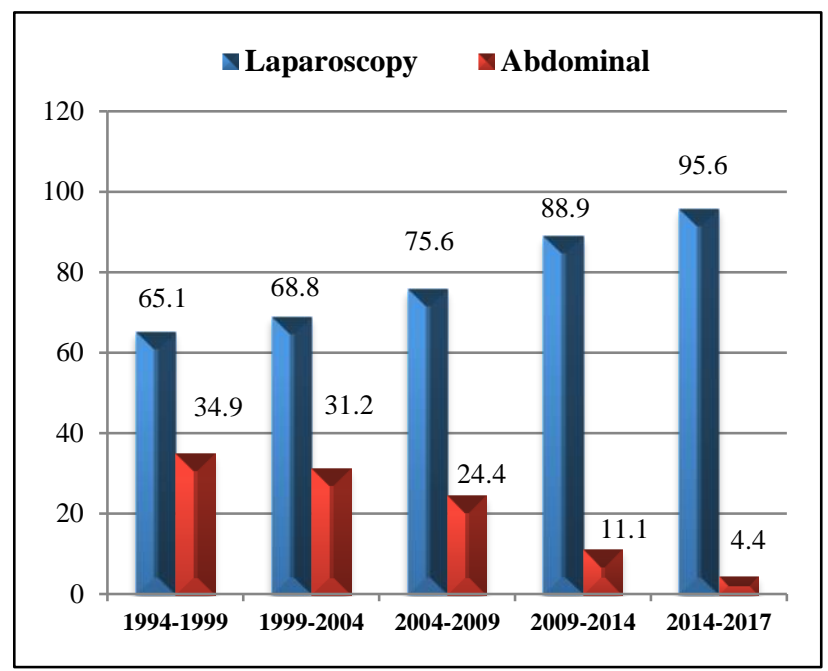

Figure 4: Selection of cases for LM/AM over the years.

Laparoscopic completion of the procedure without serious complications depends on the selection criteria which are stricter compared to those for open surgery. 
Laparoscopic approach is preferable in women with a smaller number of myomas, whilst open surgery remains the operation of choice for women with large multiple myomas.

There are no fixed guidelines as to the size or number of myomas that can be removed by laparoscopy. At the start of study, (1994-1999) the proportion of myomectomies performed by laparoscopy, was (43/66) $65.1 \%$ whereas later (2014-2017) it was (65/68) 95.6\%. As the experience with endoscopy increased more and more cases with bigger and multiple myomas could be tackled by laparoscopy (Figure 4).

Bean et al, reported (2004 to 2015), a total of 903 myomectomies. ${ }^{3}$ At the start of the study, myomectomies performed laparoscopically was less than $20 \%$, but in the following years the majority of myomectomies were performed laparoscopically $(1.5: 1)$.

The minimum and maximum ages of patients were similar in both laparoscopic and abdominal myomectomies. The maximum numbers of cases were in age groups 26-35 years.

LM was done more often for infertility (55\% versus $37.5 \%$ ) whereas AM was selected more often for abnormal uterine bleeding (AUB), big myomas and pressure symptoms ( $57.3 \%$ versus $40.2 \%)$.

The selection criteria between LM and AM were the size and the number of the myomas. Abdominal myomectomy was more frequent choice for bigger (more than $10 \mathrm{cms}$ ) and multiple myomas. The bigger myomas in laparoscopy group were done by LAM myomectomy (Figure 5).

The risk of morcellation of uterine leiomyosarcomas has recently become a 'hot' topic, since the Food and Drug Administration (FDA) warned about the use of electromechanical power morcellation. ${ }^{4}$ It should nevertheless be stressed that the prevalence of sarcoma in leiomyomas is $<0.3 \%$ and the debate on the use of electric morcellation has probably been overstated, not only because of the fear of medicolegal issues but also due to emotional reasons. ${ }^{5-7}$

In a recent study by Bojahr et al, the prevalence of sarcoma was just $0.06 \%$ in a series of 10731 uteri morcellated for myomas during laparoscopic hysterectomy. ${ }^{8}$ Similar low incidence (1/2000) was observed in a very recent meta-analysis by Pritts et al, and in a retrospective study including 4791 women in Norway Lieng et al. ${ }^{9,10}$

This complication can be avoided by extensive peritoneal lavage and careful removal of all the fragments even if some authors still have misgivings. ${ }^{11,12}$ Indeed, since their first publication, Donnez et al, no longer encountered this complication in a subsequent series of 400 laparoscopic hysterectomies (LHs), when caution was exercised and attention was paid to examine all areas of the abdominal cavity by placing the patient in the Trendelenburg and anti-Trendelenburg position and by extensive lavage. ${ }^{13}$

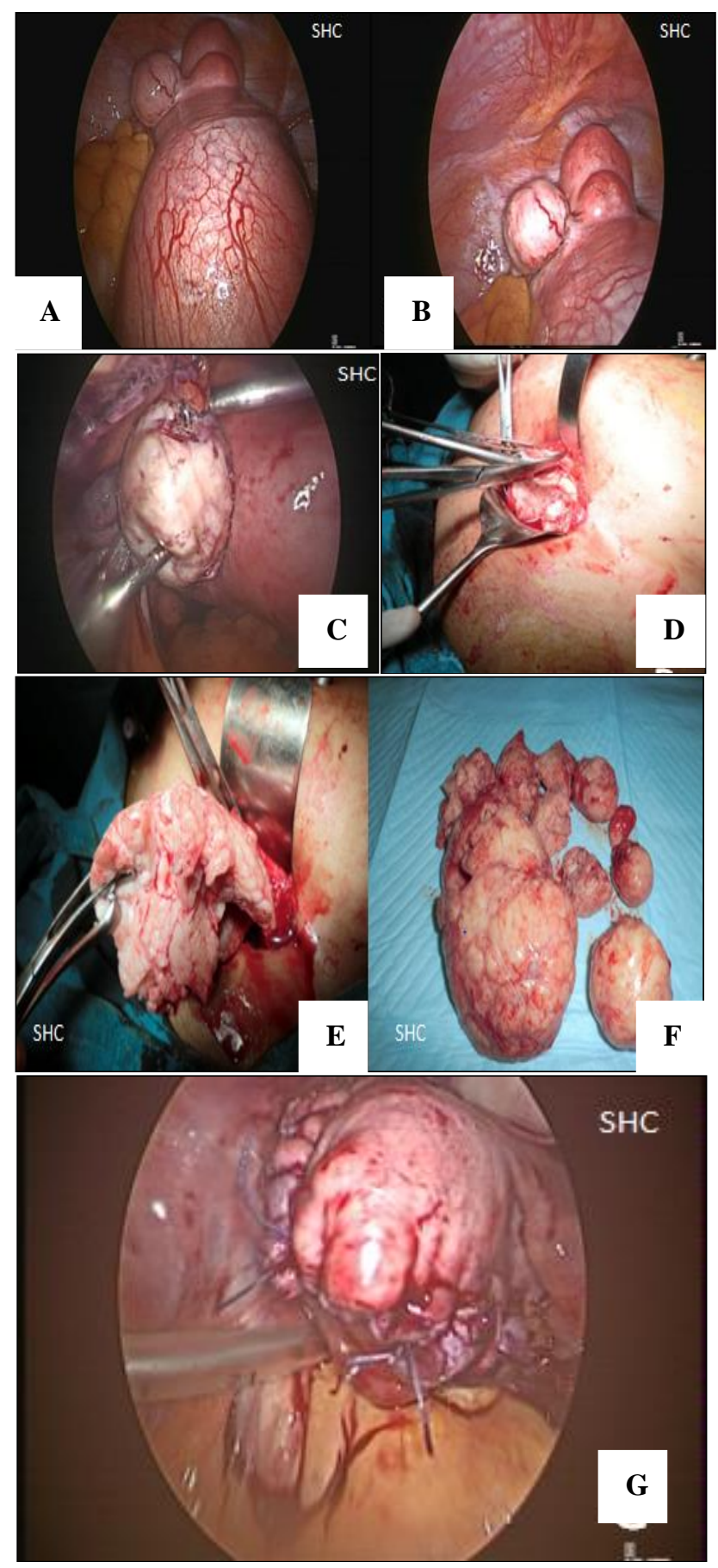

Figure 5: LAM myomectomy. A) Big fundal myoma. B) Multiple other myomas. C) Lap part myomectomy. D and E). Abdominal part-morcellation through small incision. F) Retrieved myomas.

G) Final laparoscopic picture.

The technique of power morcellation in a bag was recently suggested to minimize the risk of inadvertent tissue spread, but there is no evidence that this technique 
will not increase the rate of post-operative complications. ${ }^{5,6}$ About 5 out of 358 (1.39\%) patients in LM group and 5 out of $96(5.2 \%)$ patients in AM group underwent hysterectomy. The reasons for hysterectomy recurrence of symptoms with were recurrent myomas and stage IV endometriosis. All of them had very big multiple myomas. The gap between myomectomy and hysterectomy ranged from 5 to 15 years. More number of patients needed hysterectomy in AM group as patients with multiple and very big myomas were selected for AM. Out of 199 patients in both groups who wanted to preserve their uterus, only $10(5 \%)$ had subsequent hysterectomies. $95 \%$ of patients could avoid hysterectomy, as they had total relief from their symptoms. About 6 patients had repeat myomectomy, gap between original and repeat myomectomies is 1 to 14 years with mean gap of 7 years.

Table 3: Pregnancy rates following laparoscopic myomectomies.

\begin{tabular}{|llll|}
\hline Author & Year & Number & Pregnancy \\
\hline Hasson $^{14}$ & 1992 & 17 & $71 \%(12)$ \\
\hline Miller $^{15}$ & 1996 & 40 & $75.4 \%(30)$ \\
\hline Dubuisson $^{16}$ & 1996 & 21 & $33.3 \%(7)$ \\
\hline Ribeiro $^{17}$ & 1999 & 28 & $64 \%(18)$ \\
\hline Darai $^{18}$ & 1997 & 44 & $38.6 \%(17)$ \\
\hline Dubuisson & 1999 & 81 & $53.1 \%(4)$ \\
\hline SHC & 2017 & 157 & $40.1 \%(63)$ \\
\hline
\end{tabular}

Infertility was the indication in $198(55.3 \%)$ of LM and $36(37.5 \%$ ) in AM. Out of these 50 (41 in LM and 9 in AM) were lost for follow-up or referred back to their respective doctors or ART centers. Out of remaining 157 in LM, 63 conceived $(40.1 \%)$, this is comparable to other's results (Table 3 ). Out of 27 in AM, 10 conceived (37\%). Myomectomy is generally not advised to improve pregnancy outcomes in asymptomatic infertile women with non-cavity-distorting myomas.

However, myomectomy may be reasonable in some circumstances, including but not limited to severe distortion of the pelvic architecture complicating access to the ovaries for oocyte retrieval. ${ }^{19}$ There was no case of rupture of uterus in our series of LM or AM. The overall risk for uterine rupture was reported to be $0.32 \%$ in pregnant women with a previous caesarean section, and $0.6 \%$ to $0.8 \%$ in women with previous myomectomy. Given the potential impact of uterine rupture to mothers and their fetuses, it is essential that obstetricians perform careful follow-up for women during a pregnancy after myomectomy. Moreover, they should provide adequate counseling and explain the potential risk of uterine rupture occurring during a future pregnancy after myomectomy. ${ }^{19}$ There were 35 miscarriages in LM group and one delivery before and only 1 miscarriage and 7 successful full-term deliveries after surgery. In AM group there were 11 miscarriages and no deliveries before and no miscarriages and 4 term deliveries after surgery.

There is insufficient evidence to conclude that the presence of myomas reduces the likelihood of achieving pregnancy. However, there is fair evidence that myomectomy (open or laparoscopic) for cavity-distorting myomas (intramural or intramural with a submucosal component) improves pregnancy rates and reduces the risk of early pregnancy loss. ${ }^{19}$

\section{Complications}

Two patients in our series of Lap myomectomies had parasitic myomas. They were asymptomatic and were noticed while doing hysterectomy after several years and were removed (Figure 6).

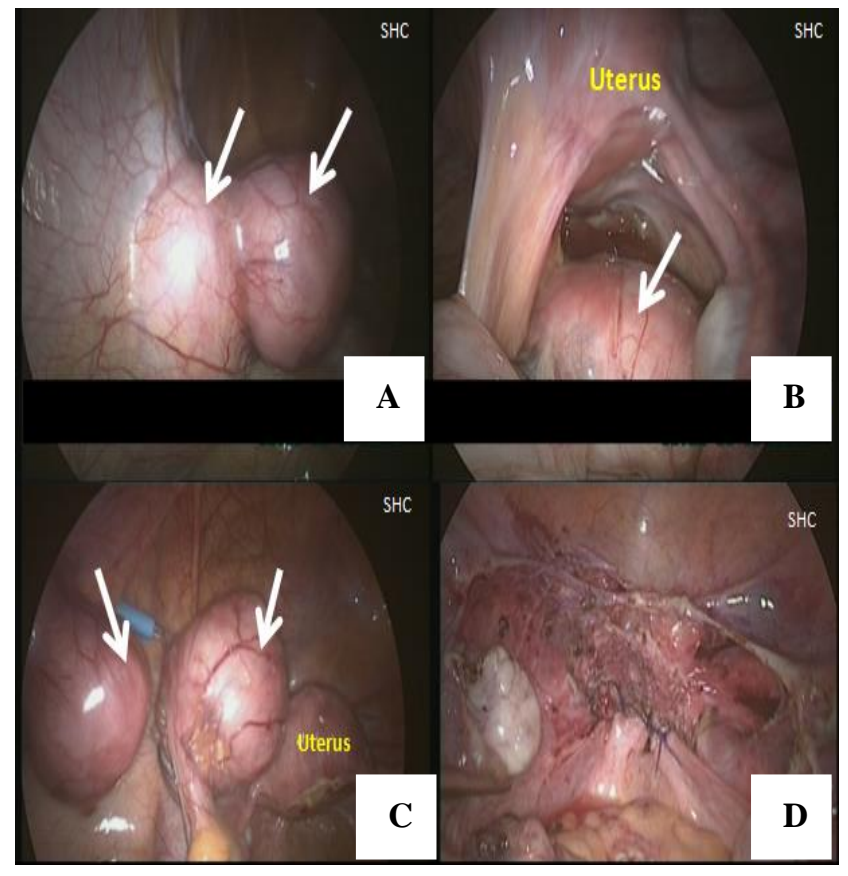

Figure 6: Parasitic myomas. A) and C) On abdominal wall. B) On rectosigmoid. D) Uterus and all parasitic myomas removed. 
One of them had recurrent of parasitic myomas again several years after hysterectomy and has a family history of fibromatosis in father and brother.

Parasitic leiomyoma is a type of leiomyoma which has been completely detached from uterus and is having independent blood from its supply new attachments.

It is regarded as a sub-type of subserosal myoma by some authors, and a complication of uterine procedures being performed for some type of uterine pathology, by others.

Literatures has only few reported cases, most of them reported in last few decades secondary to increased laparoscopic procedures of the uterus.

In a retrospective study of 423 women by Kalpana et al, $0.9 \%$ developed parasitic myomas after morcellation, which seems to be a risk factor. Only few cases of primary spontaneous parasitic myomas have been reported in literature. ${ }^{20}$

Desmoid-type fibromatosis, also called desmoid tumor, is a locally aggressive myofibroblastic neoplasm that usually arises in deep soft tissue with significant potential for local recurrence.

Multifocal desmoid tumors may occur in sporadic cases that are characterized by recurrent CTNNB1 mutations.

However, the underlying pathogenesis of multifocal desmoid tumors remains poorly understood with often aggressive clinical behavior and challenging therapeutical management. ${ }^{21}$

The complications that we encountered during these myomectomies were compared to those the other published series (Table 4). About 9 out of 358 cases $(2.5 \%)$ scheduled for laparoscopy were converted to laparotomy, reasons for conversions were dense adhesions in 3 cases, myomas in inaccessible locations in 3 cases, and intra operative haemorrhage in 3 cases. 6 out of 9 conversions were in period between 1999-2004, after 2009, there was only one conversion.
Dubuisson et al, reported a conversion rate of $16 / 213$ (7.5\% (95\% CI 3.96-1104)), which was correlated with the size of the myoma and three times more likely for anterior myomas compared with posterior or fundal location. ${ }^{16}$

Their recommendation was that laparoscopic myomectomy is a reliable technique but should only be proposed when a myoma is less than $8 \mathrm{~cm}$ and there are not more than two myomas to be removed. Sizzi et al, reported $0.3 \%$ and Bean et al, reported $0.39 \%$ conversion rates (Table 5). ${ }^{3,22}$

Over time, advances in laparoscopic imaging, energy sources and suture technology, especially ultrasound energy sources and barbed sutures in more recent years, have aided the safety and efficacy of laparoscopic surgery.

This has enabled a reduction in overall operating time and facilitated development of more complex laparoscopic surgery. This may be the reason for gradual lowering of conversion rates.

Conversion rates to laparotomy were 0.1 to $29.4 \%$, ours being $2.5 \%$. The largest series by Sizzi, had minimum and the smallest series by Marret had maximum, with possible inference that increased experience decreased conversion rates. ${ }^{22,23}$

Unexpected malignancy in our series is similar to the studies by Sinha $(0.44$ and $0.4 \%){ }^{24}$

\section{Histopathologicalexamination (HPE)}

Out of 454 cases of myomectomies histopathological examination confirmed benign leiomyoma in 450. 2 cases had smooth muscle tumor of uncertain malignant potential (STUMP).

About 2 had leiomyosarcoma and were referred to oncology institutions for further management. For both the sarcomas myomectomy was done by laparoscopy and there was no pre-operative suspicion on ultrasonography.

Table 4: Reported complications associated with laparoscopic myomectomies in other published case series. ${ }^{3}$

\begin{tabular}{|c|c|c|c|c|c|c|c|c|c|c|c|c|}
\hline & $\mathbf{N}=$ & $\begin{array}{l}\text { Un- } \\
\text { expected } \\
\text { Malig- } \\
\text { nancy, } \mathbf{n} \\
(\%)\end{array}$ & $\begin{array}{l}\text { Failure to } \\
\text { complete } \\
\text { surgery, } \mathbf{n} \\
(\%)\end{array}$ & $\begin{array}{l}\text { Hysterec- } \\
\text { tomy, } \mathbf{n} \\
(\%)\end{array}$ & $\begin{array}{l}\text { Laparo- } \\
\text { conversion } \\
\text { rate, } \mathbf{n}(\%)\end{array}$ & $\begin{array}{l}\text { Haemorr- } \\
\text { hage, } \mathbf{n} \\
(\%)\end{array}$ & $\begin{array}{l}\text { Blood } \\
\text { trans- } \\
\text { fusion, } \\
(\mathbf{n} \%)\end{array}$ & $\begin{array}{l}\text { Haematoma } \\
\text { formation, } \\
\text { n }(\%)\end{array}$ & $\begin{array}{l}\text { Bladder } \\
\text { injury, } \\
\text { n (\%) }\end{array}$ & $\begin{array}{l}\text { Bowel } \\
\text { injury } \\
(\%)\end{array}$ & $\begin{array}{l}\text { Acute } \\
\text { kidney } \\
\text { injury, } \\
\text { n }(\%)\end{array}$ & $\begin{array}{l}\text { Death, } \\
\text { n }(\%)\end{array}$ \\
\hline $\begin{array}{l}\text { Sizzi } 2007(11) * \\
\text { M }\end{array}$ & 2050 & $2(0.09)$ & $7(0.34)$ & $2(0.10)$ & $6(0.29)$ & $14(0.68)$ & $3(0.15)$ & $10(0.48)$ & - & $1(0.04)$ & $1(0.04)$ & - \\
\hline $\begin{array}{l}\text { Kumakiri } 2008 \\
914) * S\end{array}$ & 1334 & - & - & - & - & - & - & - & - & - & - & - \\
\hline Paul $20109150 * \mathrm{~S}$ & $1001 * *$ & $1(0.10)$ & - & - & $1(0.10)$ & $1(0.1)$ & $10(1.10)$ & $2(0.20)$ & $3(0.30)$ & 0 & - & $1(0.10)$ \\
\hline $\begin{array}{l}\text { Malzoni } 2006 \\
(16) * \mathrm{M}\end{array}$ & 982 & - & - & - & $13(1.29)$ & - & - & - & - & - & - & - \\
\hline $\begin{array}{l}\text { Sandberg } 2016 \\
(17) * S\end{array}$ & $731 * * *$ & - & - & $1(0.14)$ & $8(1.09)$ & - & $3(0.4)$ & - & - & $1(0.14)$ & - & - \\
\hline
\end{tabular}




\begin{tabular}{|c|c|c|c|c|c|c|c|c|c|c|c|c|}
\hline & $\mathbf{N}=$ & $\begin{array}{l}\text { Un- } \\
\text { expected } \\
\text { Malig- } \\
\text { nancy, } \mathbf{n} \\
(\%)\end{array}$ & $\begin{array}{l}\text { Failure to } \\
\text { complete } \\
\text { surgery, n } \\
(\%)\end{array}$ & $\begin{array}{l}\text { Hysterec- } \\
\text { tomy, } \mathbf{n} \\
(\%)\end{array}$ & $\begin{array}{l}\text { Laparo- } \\
\text { conversion } \\
\text { rate, } n(\%)\end{array}$ & $\begin{array}{l}\text { Haemorr- } \\
\text { hage, } \mathbf{n} \\
(\%)\end{array}$ & $\begin{array}{l}\text { Blood } \\
\text { trans- } \\
\text { fusion, } \\
(\mathrm{n} \%)\end{array}$ & $\begin{array}{l}\text { Haematoma } \\
\text { formation, } \\
\text { n (\%) }\end{array}$ & $\begin{array}{l}\text { Bladder } \\
\text { injury, } \\
\mathbf{n}(\%)\end{array}$ & $\begin{array}{l}\text { Bowel } \\
\text { injury } \\
(\%)\end{array}$ & $\begin{array}{l}\text { Acute } \\
\text { kidney } \\
\text { injury, } \\
\text { n (\%) }\end{array}$ & $\begin{array}{l}\text { Death, } \\
\text { n (\%) }\end{array}$ \\
\hline $\begin{array}{l}\text { Serracchioli } 2006 \\
\text { (19) }\end{array}$ & 514 & - & - & - & - & - & - & - & - & - & - & - \\
\hline Yoo 2007 (20) & 512 & - & - & - & - & - & $7(1.14)$ & - & $1(0.20)$ & $1(0.20)$ & - & - \\
\hline $\begin{array}{l}\text { Sinha } 2008(21) * \\
\text { S }\end{array}$ & 505 & $2(0.40)$ & - & $1(0.20)$ & $1(0.20)$ & - & $31(6.14)$ & $1(0.20)$ & - & - & - & - \\
\hline Radosa 2012 (22) & $451^{* * *}$ & - & - & - & $1(0.22)$ & - & $3(0.67)$ & - & $1(0.22)$ & $3(0.67)$ & - & - \\
\hline Saccardi 2014 (23) & 444 & - & - & - & $6(1.35)$ & - & $2(0.45)$ & - & - & - & - & - \\
\hline Landi 2001 (24) & 368 & - & - & - & - & - & $10(2.7)$ & $2(0.57)$ & - & - & - & - \\
\hline $\begin{array}{l}\text { Altgassen } 2006 \\
(25)\end{array}$ & 351 & - & $1(0.28)$ & $1(0.28)$ & $1(0.28)$ & - & $2(0.57)$ & 0 & - & $3(0.85)$ & - & - \\
\hline Rosetti 2007 (26) & 332 & - & - & - & $3(0.90)$ & $2(0.57)$ & 0 & 0 & - & $\begin{array}{l}1 \\
(0.30)\end{array}$ & $\begin{array}{l}1 \\
(0.30)\end{array}$ & - \\
\hline Tinelli 2012 (28) & 235 & - & - & - & - & - & 0 & - & - & - & - & - \\
\hline $\begin{array}{l}\text { Dubuisson } 1996 \\
\text { (12) }\end{array}$ & 213 & - & - & - & $16(7.51)$ & - & - & - & - & - & - & - \\
\hline Mettler 2005 (29) & 178 & - & - & - & - & - & - & - & - & - & - & - \\
\hline Malzoni 2003 (30) & 144 & - & - & - & $2(1.39)$ & - & $1(0.70)$ & $1(0.70)$ & - & - & - & - \\
\hline Marret 2004 (31) & 126 & - & - & - & $37(29.4)$ & - & 0 & 0 & - & - & - & - \\
\hline Dessolle 2001 (33) & 88 & - & - & - & - & - & 0 & 0 & - & $1(1.14)$ & - & - \\
\hline SHC (358) & 358 & $2(0.44)$ & - & $5(1.39)$ & $9(2.5)$ & $10(2.7)$ & $10(2.7)$ & $2(0.44)$ & - & - & - & - \\
\hline
\end{tabular}

Table 5: Laparoscopic conversions to abdominal myomectomy a comparative study.

\begin{tabular}{|lllll|}
\hline Study group & Total number & Number of conversions & $\%$ & Hysterectomy \\
\hline Sizzi et $\mathrm{al}^{22}$ & 2050 & 6 & $0.3 \%$ & 1 \\
\hline Bean et al & 514 & 2 & $0.39 \%$ & 0 \\
\hline Dubuisson et al ${ }^{36}$ & 213 & 16 & $7.5 \%$ & 0 \\
\hline SHC & 358 & 9 & $2.51 \%$ & 0 \\
\hline
\end{tabular}

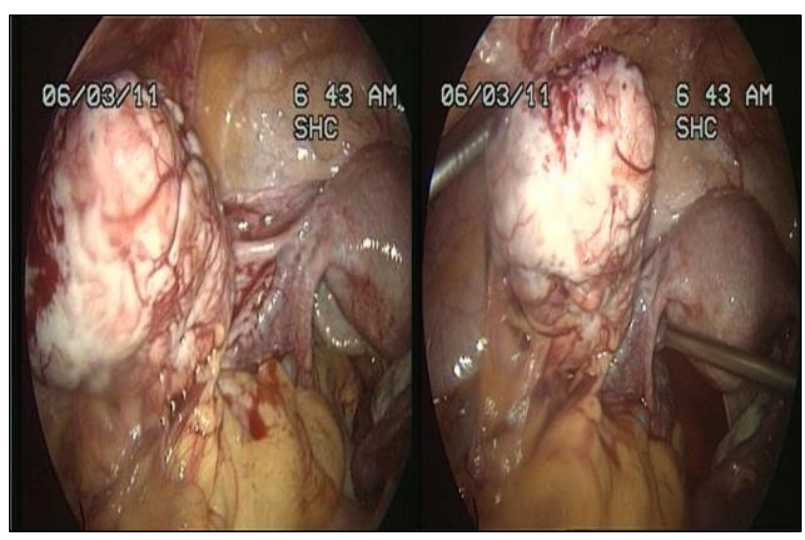

Figure 7: Sarcoma. A) Normal uterus with myoma attached to omentum. B) Myomectomy in progress.

One patient was 30 years old P1L1 with broad ligament myoma on USG. Laparoscopy revealed a $5 \times 5 \mathrm{cms}$ myoma attached to the omentum without any attachment to the uterus, tubes or ovaries (considered parasitic myoma) (Figure 7). Myomectomy was done and HPE report showed high grade sarcoma.

The other patient with leiomyomsarcoma was P2L2, 35 years old with symptomatic myoma of $3 \mathrm{cms}$ size, underwent routine laparoscopic myomectomy. HPE showed sarcoma. Both of them were immediately referred to oncology institutes for further management and were treated successfully.

One patient with STUMP was lost for follow-up and the second patient came back to us recently ( 7 years after initial myomectomy) with large multiple myomas (36 weeks size uterus), with high vascularity, still undecided for surgery as she is nulliparous. The incidence of leiomyosarcoma in our series was $0.44 \%$, similar result was quoted by many other authors Bojahr et al, Pritts et al, Lieng et al. . $^{-10}$

Similar trend was reported by Bean et al. In this study, the two cases in which histology revealed a STUMP, were both pre-menopausal women aged 37 years and 39 years, who had myomas measuring $60 \mathrm{~mm}$ in diameter.

The woman who had a suspicious uterine mass that underwent open excision and histology proved to be a leiomyosarcoma, was 32 years old with no risk factors for malignancy and $10 \mathrm{cms}$ myoma on ultrasound. ${ }^{3}$ Some have suggested pre-operative histological diagnosis prior to LM in women who have risk factors for malignancy before morcellation is considered. ${ }^{25}$ In order to obtain a tissue sample, without risking dissemination of cell into the peritoneal cavity, a transcervical approach can be considered. This is carried out under ultrasound or CT guidance, to ensure accurate location of the biopsy and to 
minimize risk to other structures, including the uterine serosa.

Although the potential for trans-tubal passage of cells remains, the risk of intra-peritoneal spread is reduced with this method. ${ }^{26}$

\section{CONCLUSION}

Myomas are associated with significant decrease in quality of life. Myomectomy is the most common approach for management of symptomatic myomas in women who desire future fertility or wish uterine preservation. For successful surgery, careful patient selection with detailed pre-operative imaging, clinical examination and counseling are important. Selection of appropriate route and type of surgery is mandatory to achieve a good result with minimum complications. This study of LM and AM was done to analyse the feasibility, complications and outcomes. Both the methods were found to be safe, feasible and provided good result. With increasing experience bigger and multiple myomas could be tackled by LM, which has several advantages over AM.

Funding: No funding sources

Conflict of interest: None declared

Ethical approval: The study was approved by the Institutional Ethics Committee

\section{REFERENCES}

1. Falcone T, William H. Surgical management of leiomyomas for fertility or uterine preservation. Obstet Gynecol. 2013;121:856-68.

2. Smith BA, Holland T. Laparoscopic myomectomy: a review of alternatives, techniques and controversies. Obstetrician Gynaecol. 2018;20(4):261-8.

3. Bean EMR, Cutner A, Holland T, Vashisht A, Jurkovic D, Saridogan E. Laparoscopic myomectomy: a single centre retrospective review of 514 patients. J Minimally Inv Gynecol. 2017;24(3):485-93.

4. Ton R, Kilic GS, Phelps JY. A medical-legal review of power morcellation in the face of the recent FDA warning and litigation. J Minim Invasive Gynecol. 2015;22:564-72.

5. Donnez J, Donnez O, Dolmans MM. With the advent of selective progesterone receptor modulators, what is the place of myoma surgery in current practice? Fertil Steril. 2014;102:640-8.

6. Donnez J, Vázquez F, Tomaszewski J, Nouri K, Bouchard P, Fauser BC, et al. Long-term treatment of uterine fibroids with ulipristal acetate. Fertil Steril. 2014;101:1565-73.

7. Parker WH, Kaunitz AM, Pritts EA, Olive DL, Chalas E, Clarke-Pearson DL, et al. Leiomyoma Morcellation Review Group. U.S. Food and Drug Administration's Guidance regarding morcellation of leiomyomas: well-intentioned, but is it harmful for women? Obstet Gynecol. 2016;127:18-22.

8. Bojahr B, De Wilde RL, Tchartchian G. Malignancy rate of 10,731 uteri morcellated during laparoscopic supracervical hysterectomy (LASH). Arch Gynecol Obstet. 2015;292:665-72.

9. Pritts EA, Vanness DJ, Berek JS, Parker W, Feinberg $\mathrm{R}$, Feinberg $\mathrm{J}$, et al. The prevalence of occult leiomyosarcoma at surgery for presumed uterine fibroids: a meta-analysis. Gynecol Surg. 2015;12(3):165-77.

10. Lieng M, Berner E, Busund B. Risk of morcellation of uterine leiomyosarcomas in laparoscopic supracervical hysterectomy and laparoscopic myomectomy, a retrospective trial including 4791 women. J Minim Invasive Gynecol. 2015;22:410-4.

11. Donnez O, Squifflet J, Leconte I, Jadoul P, Donnez J. Posthysterectomy pelvic adenomyotic masses observed in 8 cases out of a series of 1405 laparoscopic subtotal hysterectomies. J Minim Invasive Gynecol. 2007; 14:156-60.

12. Pereira N, Bender JL, Hancock K, Lekovich JP, Elias RT, Kligman I, et al. Routine monitoring of liver, renal, and hematologic tests after single- or doubledose methotrexate treatment for ectopic pregnancies after in vitro fertilization. J Minim Invasive Gynecol. 2015;22:1266-70.

13. Donnez O, Donnez J. A series of 400 laparoscopic hysterectomies for benign disease: a single centre, single surgeon prospective study of complications confirming previous retrospective study. BJOG. 2010;117:752-5.

14. Hasson HM, Rotman C, Rana N. Laparoscopic myomectomy. Obstet Gynaecol. 1992;80:884-8.

15. Miller, Mary J. Laparoscopic myomectomy in the infertile woman. J Am Assoc Gynaecol Laparoscop. 1996;3(4):525-32.

16. Dubuisson JB, Chapron C. Difficulties and complications of laparoscopic myomectomy. J Gynecol Surg. 1996;12(3):159-65.

17. Ribeiro, Reich H. Laparoscopic myomectomy and pregnancy outcome in infertile patients. Fertility Sterility. 1999;71(3):571-4.

18. Darai E, Dechaud H. Fertility after laparoscopic myomectomy: preliminary results. Human Repro. 1997;12(9):1931-4.

19. Removal of myomas in asymptomatic patients to improve fertility and/or reduce miscarriage rate: a guideline. Pract Com Am Society Repro Med Ferti Ster. 2017;108(3).

20. Kalpana B, Soumya R. Rare presentation of a case of primary parasitic leiomyoma with concurrent uterine leiomyomas. Int $\mathrm{J}$ Reprod Contracept Obstet Gynecol. 2018;7(6):2503-5.

21. Beker EM. Multifocal occurrence of extra-abdominal desmoid type fibromatosis-a rare manifestation. A clinicopathological study of 6 sporadic cases and hereditary case. Ann Diagnost Pathol. 2018;35:3841. 
22. Sizzi O, Rossetti A, Malzoni M, Minelli L, La Grotta F, Soranna L, et al. Italian multicenter study on complications of laparoscopic myomectomy. J Minimally Invasive Gynecol. 2007;14(4):453-62.

23. Marret H, Chevillot M, Giraudeau B. of the French TS, of 484 Gynaecology S. A retrospective multicentre study comparing myomectomy by laparoscopy and laparotomy in current surgical practice: What are the best patient selection criteria? Eu J Obstet Gynecol Repro Biol. 2004;10:117(1):826.

24. Sinha R, Hegde A, Mahajan C, Dubey N, Sundaram M. Laparoscopic myomectomy: do size, number, and location of the myomas form limiting factors for laparoscopic myomectomy?. J Minimally Invasive Gynecol. 2008;15(3):292-300.
25. Tulandi T, Ferenczy A. Biopsy of uterine leiomyomata and frozen sections before laparoscopic morcellation. J Minimally Invasive Gynecol. 2014;21(5):963-6.

26. Kawamura N, Ichimura $\mathrm{T}$, Ito $\mathrm{F}$, Shibata $\mathrm{S}$, Takahashi K, Tsujimura A, et al. Transcervical needle biopsy for the differential diagnosis between uterine sarcoma and leiomyoma. Cancer. 2002;94(6):1713-20.

Cite this article as: Devi YS, Swapna YK, Naidu TK, Vaddiraju GB. Myomectomy for uterine preservation and fertility. Int J Reprod Contracept Obstet Gynecol 2019;8:2668-77. 